\title{
The diagnostic utility of immunohistochemistry and electron microscopy in distinguishing between peritoneal mesotheliomas and serous carcinomas: a comparative study
}

\author{
Nelson G Ordóñez \\ Department of Pathology, MD Anderson Cancer Center, The University of Texas, TX, USA
}

\begin{abstract}
The histologic distinction between peritoneal epithelioid mesotheliomas and serous carcinomas diffusely involving the peritoneum may be difficult, but it can be facilitated by the use of immunohistochemistry and electron microscopy. D2-40 and podoplanin are two recently recognized lymphatic endothelial markers that can be expressed in normal mesothelial cells and mesotheliomas. The purpose of this study is to compare the value of these new mesothelial markers with those that are commonly used for discriminating between mesotheliomas and serous carcinomas, and also to determine the current role of electron microscopy in distinguishing between these malignancies. A total of $\mathbf{4 0}$ peritoneal epithelioid mesotheliomas and $\mathbf{4 5}$ serous carcinomas of the ovary (15 primary, 30 metastatic to the peritoneum) were investigated for the expression of the following markers: D2-40, podoplanin, calretinin, keratin 5/6, thrombomodulin, MOC-31, Ber-EP4, B72.3 (TAG-72), BG-8 (Lewis ${ }^{\curlyvee}$ ), CA19-9, and leu-M1 (CD15). All 40 (100\%) of the mesotheliomas reacted for calretinin, $93 \%$ for D2-40, $93 \%$ for podoplanin, $93 \%$ for keratin $5 / 6,73 \%$ for thrombomodulin, $13 \%$ for Ber-EP4, $5 \%$ for MOC$31,3 \%$ for BG-8, and none for B72.3, CA19-9, or leu-M1. All $45(100 \%)$ serous carcinomas were positive for Ber-EP4, 98\% for MOC-31, 73\% for B72.3, 73\% for BG-8, 67\% for CA19-9, 58\% for leu-M1, 31\% for keratin $5 / 6,31 \%$ for calretinin, $13 \%$ for D2-40, 13\% for podoplanin, and $4 \%$ for thrombomodulin. After analyzing the results, it is concluded that Ber-EP4 and MOC-31 are the best negative mesothelioma markers for differentiating between epithelioid mesotheliomas and serous carcinomas. The best discriminators among the positive markers for mesotheliomas are D2-40, podoplanin, and calretinin. From a practical point of view, Ber-EP4 and MOC-31, in combination with calretinin, and/or D2-40 or podoplanin allow the differential diagnosis to be established between mesothelioma and serous carcinoma in nearly all instances. As a clear distinction could be made between these two malignancies in all of the cases in which electron microscopy was performed, this technique can be very useful in establishing the correct diagnosis when the immunohistochemical results are equivocal or further support of a diagnosis of either mesothelioma or serous carcinoma is needed.
\end{abstract}

Modern Pathology (2006) 19, 34-48. doi:10.1038/modpathol.3800471; published online 29 July 2005

Keywords: Immunohistochemistry; electron microscopy; mesothelioma; serous carcinoma; D2-40; podoplanin

Epithelioid mesotheliomas, especially those presenting papillary or tubulopapillary growth patterns, can be difficult to differentiate from primary or metastatic serous papillary carcinomas diffusely involving the peritoneum due to overlapping morphologic features. It is generally accepted that

Correspondence: Dr NG Ordóñez, Department of Pathology, MD Anderson Cancer Center, The University of Texas, 1515 Holcombe Avenue, Box 85/Pathology Department, Houston, TX 77030, USA. E-mail: nordonez@mdanderson.org

Received 11 April 2005; revised and accepted 24 June 2005; published online 29 July 2005 immunohistochemical studies can be helpful in establishing the correct diagnosis, but, because a specific marker for either mesothelioma or serous carcinoma has not yet been identified, the differential diagnosis between these malignancies is based on the use of immunohistochemical panels that combine markers that are commonly expressed in epithelioid mesotheliomas, but not in serous carcinomas with markers that are often expressed in serous carcinomas but not in mesotheliomas. ${ }^{1,2}$ In 1998, in the largest study on the role of immunohistochemistry in the diagnosis of peritoneal mesotheliomas, 16 markers that at that time were 
considered to have some potential utility in the diagnosis of this tumor were evaluated. ${ }^{2}$ The conclusion of that investigation was that calretinin, thrombomodulin, and keratin 5/6 were the best positive mesothelioma markers and MOC-31, B72.3, Ber-EP4, CA19-9, and leu-M1 (CD15) were the best negative mesothelioma markers for differentiating peritoneal epithelioid malignant mesotheliomas from papillary serous carcinomas diffusely involving the peritoneum. Several new markers have since been investigated as to their potential utility in the diagnosis of mesothelioma. These include Ecadherin, ${ }^{3-6} \mathrm{~N}$-cadherin, ${ }^{4,6,7}$ Wilms' tumor protein 1 (WT1), ${ }^{5,8,9} \mathrm{CD} 44 \mathrm{~S},{ }^{1,5,9,10}$ mesothelin, ${ }^{11}$ and the BG-8 antibody that reacts with the Lewis ${ }^{\mathrm{Y}}$ antigen..$^{5,7,9,12,13}$ Among these markers, only BG-8 has been found to be useful in discriminating between epithelioid mesotheliomas and ovarian serous carcinomas by the demonstration of strong positivity in the large majority of serous carcinomas of the ovary, but not in mesotheliomas which are almost invariably negative or rarely weakly positive. ${ }^{5}$ As WT1 and mesothelin were found to be strongly expressed in serous carcinomas of the ovary, these markers have no utility in discriminating these tumors from mesotheliomas. ${ }^{5,11,14}$ WT1 and mesothelin were found to be useful positive markers that could assist in distinguishing epithelioid mesotheliomas, which usually express these markers, from lung adenocarcinomas which are negative. ${ }^{5,9,11,15}$ None of the other markers proved to have any utility.

Podoplanin and the monoclonal antibody D2-40 are two markers that have recently been recognized to be highly specific for lymphatic endothelium. ${ }^{16-19}$ Two recent investigations on D2-40 (one published only in abstract form) have indicated that, because this antibody often reacts with epithelioid mesotheliomas, but not with carcinomas, it could be useful in discriminating between these malignancies. ${ }^{20,21}$ Only one of these studies, ${ }^{20}$ however, included serous carcinomas of the ovary in their general group of carcinomas of various histologic types and origins. In that investigation, the authors reported some differences in D2-40 reactivity between mesotheliomas and serous carcinomas, but they did not draw any conclusions regarding whether or not immunostaining for this marker had any utility in the differential diagnosis between these two tumors. ${ }^{20}$ Kimura and Kimura ${ }^{22}$ recently reported that podoplanin is also commonly expressed in epithelioid mesotheliomas, but not in carcinomas, and they, therefore, suggested that this marker could assist in the differential diagnosis of these tumors.

The purpose of this study is to review the current information on the value of the various markers which, at present, are considered to be useful in differentiating between epithelioid peritoneal mesotheliomas and serous carcinomas, to evaluate the potential utility of D2-40 and podoplanin in this differential diagnosis, and to determine the current role of electron microscopy in discriminating between these malignancies, especially since this technique was, for some time, considered to be the gold standard in the diagnosis of mesothelioma. To my knowledge, only two comparative studies on the value of electron microscopy in distinguishing mesotheliomas from serous carcinomas have been published, ${ }^{23,24}$ and the number of cases in both studies was rather limited.

\section{Materials and methods}

The material used in this study was obtained from the Department of Pathology at the University of Texas MD Anderson Cancer Center. It consisted of 40 cases of peritoneal malignant epithelioid mesothelioma, and 45 serous carcinomas of the ovary (15 primary, 30 metastatic to the peritoneum). Twenty-five of the mesotheliomas occurred in women and 15 in men. The diagnosis in all of the mesothelioma cases was made using WHO criteria on hematoxylin and eosin-stained sections combined with immunohistochemical and clinical features. ${ }^{25}$ Immunohistochemical studies were performed on formalin-fixed, paraffin-embedded tissue sections using the avidin-biotin-peroxidase complex method in a Dako AutoStainer (Carpinteria, CA, USA). The primary antibodies that were used are listed in Table 1. The immunostaining was done

Table 1 Antibodies used in this study

\begin{tabular}{|c|c|c|c|c|}
\hline Marker & Source & Tyре & Dilution & Antigen retrieval \\
\hline $\mathrm{D} 2-40$ & Signet Laboratories (Dedham, MA, USA) & MAb & $1: 25$ & Yes (Tris-EDTA) \\
\hline Podoplanin & AngioBio Company (Del Mar, CA, USA) & $\mathrm{MAb}$ & $1: 40$ & Yes (citrate) \\
\hline Calretinin & Zymed (South San Francisco, CA, USA) & PAb (rabbit) & $1: 20$ & Yes (citrate) \\
\hline Keratin 5/6 & Dako Corporation (Carpinteria, CA, USA) & D5/16B4 MAb & $1: 25$ & Yes (citrate) \\
\hline Thrombomodulin & Dako Corporation & $1005 \mathrm{MAb}$ & $1: 50$ & Yes (citrate) \\
\hline BG-8 (Lewis ${ }^{\mathrm{Y}}$ ) & Signet Laboratories & BG-8 MAb & $1: 50$ & Yes (citrate) \\
\hline MOC-31 & Dako Corporation & MAb & $1: 50$ & Yes (citrate) \\
\hline CA19-9 & Dako Corporation & MAb & $1: 50$ & No \\
\hline TAG-72 & BioGenex (San Ramon, CA, USA) & B72.3 MAb & $1: 300$ & No \\
\hline CD15 & Becton-Dickinson (Mountainview, CA, USA) & Leu-M1 MAb & $1: 40$ & Yes (Tris-EDTA) \\
\hline Ber-EP4 & Dako Corporation & MAb & $1: 30$ & Yes (enzymatic digestion) \\
\hline
\end{tabular}


using the LSAB2 peroxidase kit (Dako). To enhance the immunostaining, a heat epitope retrieval procedure was performed using a Black-and-Decker (Shelton, CT, USA) vegetable steamer as previously described. ${ }^{9}$ Depending on the antibody, the buffer solutions used were either sodium citrate buffer, $\mathrm{pH}$ 6.0, or a 10:1 solution of Tris-EDTA buffer, pH 8.0. Enzymatic pretreatment with $0.2 \%$ protease, type XXIV (Sigma Chemical, St Louis, MO, USA) in Tris-

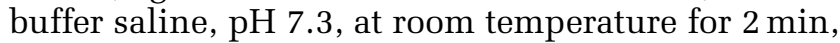
was used with the Ber-EP4 antibody. The antigenantibody reaction was visualized using 3-amino-9ethylcarbazole or 3,3'-diaminobenzidine tetrahydrochloride as chromogen. To evaluate the specificity of the antibodies, known positive and negative tissues were used as controls. The immunostaining was graded on a sliding scale of $1+$ to $4+$ according to the percentage of reactive cells (trace, $<1 \% ; 1+$, $1-25 \% ; 2+, 26-50 \% ; 3+, 51-75 \% ; 4+, 76-100 \%$ ).

Ultrastructural studies were performed in 15 mesotheliomas and 20 serous carcinomas. Samples for electron microscopy were fixed in $2 \%$ glutaraldehyde in phosphate buffer, post-fixed in $1 \%$ osmium tetroxide, and embedded in Epon epoxy resin. Ultrathin sections were stained with uranyl acetate and lead citrate.

\section{Results}

\section{Immunohistochemical Findings}

The immunohistochemical results are summarized in Table 2.

\section{D2-40}

In all, $37(93 \%)$ of the 40 mesotheliomas stained with the D2-40 antibody. The reaction was strong and diffuse $(3+$ or $4+)$ in the large majority of the cases, and it was characterized by a continuous, thick, membranous staining pattern along the apical cell membranes in all of the better differentiated and papillary tumors (Figure 1a). In the solid or lessdifferentiated tumors, the reaction was less consistent, at times appearing to encircle the cells, or, in other instances, exhibiting a discontinuous membranous staining pattern (Figure 1b). Six (13\%) of the 45 serous carcinomas stained with the D2-40 antibody. In all of the cases, the reaction occurred on the apical surface of the cell, and it was graded as $2+$ in two cases and $1+$ in the remaining four (Figure 1c).

\section{Podoplanin}

Podoplanin expression was demonstrated in the same 37 mesothelioma cases that reacted with the D2-40 antibody. The reaction was graded as $4+$ in 16 cases, $3+$ in $8,2+$ in 9 , and $1+$ in 4 . The staining pattern was similar to that seen with the D240 antibody (Figure 1d, e). Six (13\%) of the 45 serous carcinomas exhibited podoplanin expression, and, in all instances, the staining occurred along the apical surface of the cells in a continuous pattern (Figure 1f). In two cases, the reaction was graded as $2+$ and in four as $1+$.

\section{Calretinin}

All $40(100 \%)$ mesothelioma cases reacted for calretinin. In nearly all instances, the staining was strong and diffuse $(3+$ or $4+)$ and occurred in both the cytoplasm and the nucleus (Figure 2a). In all, 14 $(31 \%)$ of the 45 serous carcinomas were calretinin positive. In three of the cases, the reaction was graded as $3+$, in three as $2+$, in seven as $1+$, and trace in the remaining one.

\section{Keratin 5/6}

In all, 37 (93\%) of the 40 mesotheliomas exhibited keratin 5/6 expression. The staining was strong $(3+$ and $4+$ ) and evenly distributed throughout the cytoplasm in 22 of these cases. Keratin $5 / 6$ positivity was observed in $14(31 \%)$ of the 45 serous carcinomas (Figure 2b). In four cases, the reaction

Table 2 Immunohistochemical results

\begin{tabular}{|c|c|c|c|c|c|c|c|c|c|c|c|c|}
\hline \multirow[t]{3}{*}{ Marker } & \multicolumn{6}{|c|}{ Peritoneal epithelioid mesotheliomas } & \multicolumn{6}{|c|}{ Papillary serous carcinomas } \\
\hline & \multirow{2}{*}{$\begin{array}{c}\mathrm{n}=40 \\
+\operatorname{Cases}(\%)\end{array}$} & \multicolumn{5}{|c|}{ Grade of reactivity } & \multirow{2}{*}{$\begin{array}{c}\mathrm{n}=45 \\
+ \text { Cases (\%) }\end{array}$} & \multicolumn{5}{|c|}{ Grade of reactivity } \\
\hline & & Trace & $1+$ & $2+$ & $3+$ & $4+$ & & Trace & $1+$ & $2+$ & $3+$ & $4+$ \\
\hline $\mathrm{D} 2-40$ & $37(93)$ & 0 & 4 & 7 & 9 & 17 & $6(13)$ & 0 & 4 & 2 & 0 & 0 \\
\hline Podoplanin & 37 (93) & 0 & 4 & 9 & 8 & 16 & $6(13)$ & 0 & 4 & 2 & 0 & 0 \\
\hline Calretinin & $40(100)$ & 0 & 0 & 1 & 9 & 30 & $14(31)$ & 1 & 7 & 3 & 3 & 0 \\
\hline Keratin 5/6 & $37(93)$ & 1 & 3 & 11 & 12 & 10 & $14(31)$ & 3 & 7 & 4 & 0 & 0 \\
\hline Thrombomodulin & $29(73)$ & 1 & 6 & 11 & 7 & 4 & $2(4)$ & 1 & 1 & 0 & 0 & 0 \\
\hline MOC-31 & $2(5)$ & 1 & 1 & 0 & 0 & 0 & 44 (98) & 1 & 1 & 4 & 9 & 29 \\
\hline Ber-EP4 & $5(13)$ & 2 & 3 & 0 & 0 & 0 & $45(100)$ & 0 & 1 & 2 & 8 & 34 \\
\hline B72.3 (TAG-72) & $0(0)$ & 0 & 0 & 0 & 0 & 0 & $33(73)$ & 7 & 13 & 6 & 4 & 3 \\
\hline BG-8 (Lewis ${ }^{\mathrm{y}}$ ) & $2(3)$ & 1 & 0 & 0 & 0 & 0 & $33(73)$ & 2 & 8 & 9 & 6 & 8 \\
\hline CA19-9 & $0(0)$ & 0 & 0 & 0 & 0 & 0 & $30(67)$ & 1 & 15 & 13 & 1 & 0 \\
\hline Leu-M1 (CD15) & $0(0)$ & 0 & 0 & 0 & 0 & 0 & $26(58)$ & 0 & 9 & 10 & 7 & 0 \\
\hline
\end{tabular}



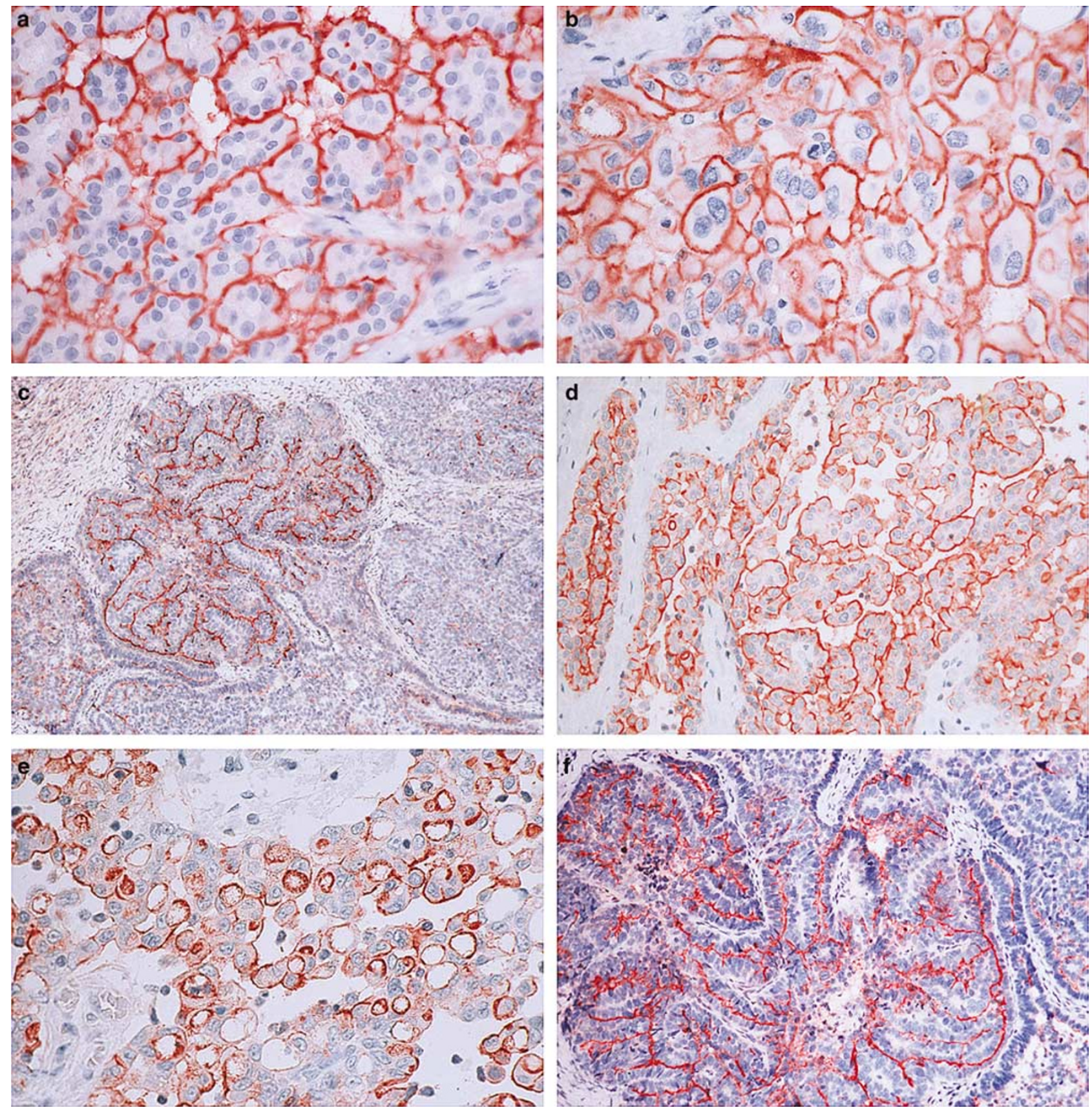

Figure 1 (a) Strong D2-40 reactivity is seen along the apical surface of the cells in a papillary mesothelioma. (b) Solid area of a mesothelioma reacting with the D2-40 antibody. In some cells, the reaction appears to be encircling the entire cell, whereas in others it is discontinuous. (c) Serous carcinoma metastatic to the peritoneum, showing an area of continuous D2-40 positivity along the apical cell membrane. (d) Papillary mesothelioma exhibiting strong podoplanin positivity on the apical surface of the cells. (e) In this mesothelioma stained for podoplanin, there is an irregular, discontinuous reactivity along the apical surface of the cells. Strong reactivity on the cell membrane of what appears to be intracytoplasmic lumens is also seen. (f) The same serous carcinoma as shown in Figure 1c demonstrating an area of podoplanin positivity.

was graded $2+$, in seven $1+$, and trace in the remaining three.

\section{Thrombomodulin}

Out of the 40 mesotheliomas, $29(73 \%)$ showed TM reactivity along the cell membrane (Figure 2c). Only two $(4 \%)$ of the serous carcinomas exhibited positivity for this marker in a few tumor cells.
MOC-31

Out of the 45 serous carcinoma cases, 44 (98\%) stained with the MOC-31 antibody. The reaction was often strong and occurred in the cytoplasm and along the cell membrane (Figure 2d). In 29 of the cases, the reaction was graded as $4+$, in nine as $3+$, in four as $2+$, and $1+$ and trace in one case each. Only two $(5 \%)$ mesothelio- 

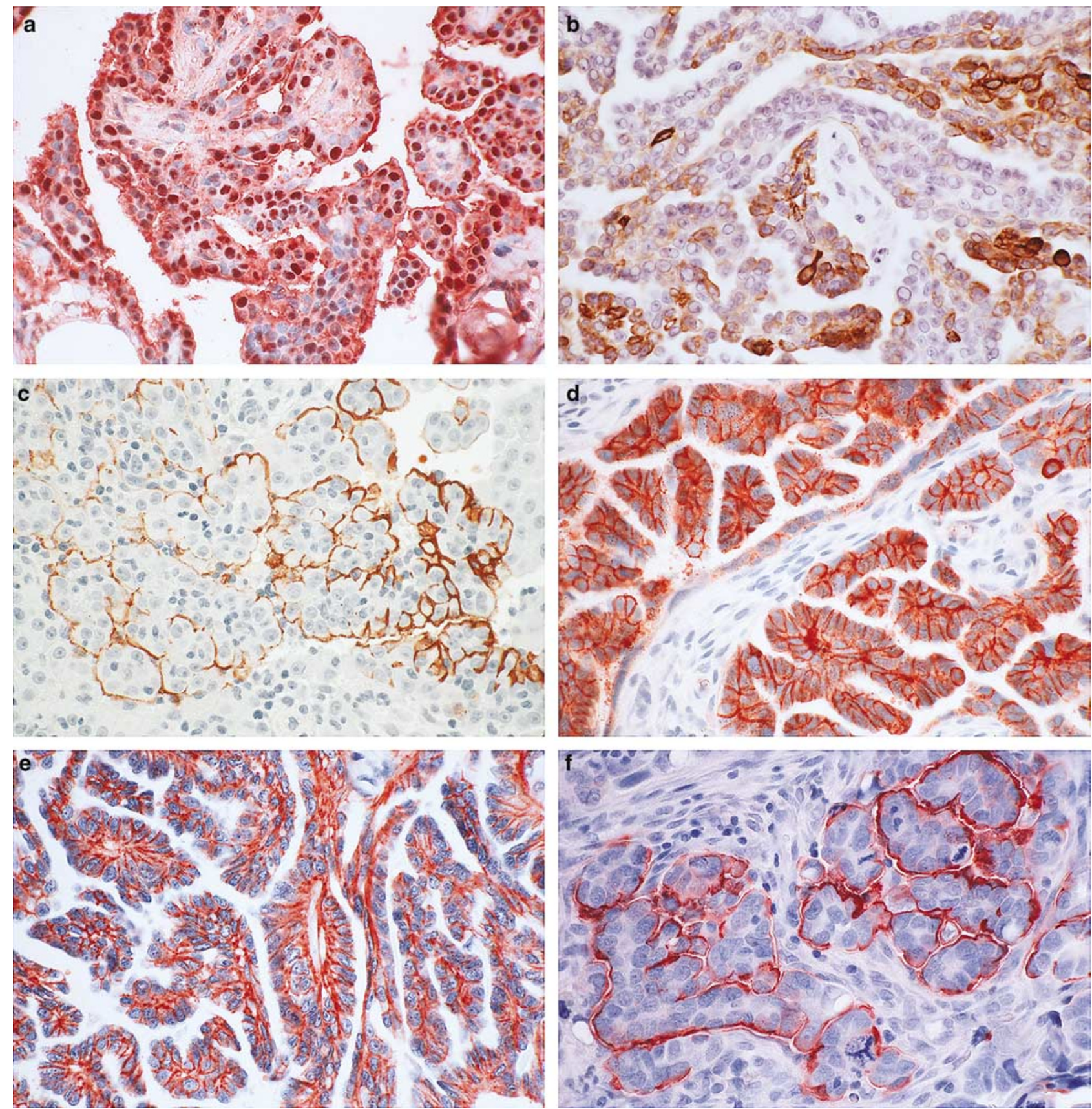

Figure 2 (a) Mesothelioma showing strong nuclear and cytoplasmic positivity for calretinin. (b) An area of positivity for keratin 5/6 in a serous carcinoma. (c) Positivity for thrombomodulin is seen along the cell membrane of a mesothelioma. (d) Serous carcinoma displaying strong cytoplasmic and membranous reactivity with the MOC-31 antibody. (e) Serous carcinoma exhibiting strong reactivity with the BerEP4 antibody. (f) Serous carcinoma showing membranous positivity for B72.3.

mas exhibited MOC-31 positivity in a few tumor cells.

\section{Ber-EP4}

All $(100 \%)$ of the 45 serous carcinomas reacted with the Ber-EP4 antibody. In the large majority of the cases, the reaction was strong and diffuse ( 34 were graded $4+$ and eight $3+$ ) (Figure 2e). Only five $(13 \%)$ of the mesotheliomas exhibited Ber-EP4 positivity in a limited number of cells. The staining was graded $1+$ in three cases, and trace in the remaining case. The reaction in both types of tumors occurred along the cell membranes.

B72.3

Out of the 45 serous carcinomas, $33(73 \%)$ stained with the B72.3 antibody and the reaction often occurred along the apical surface of the cells (Figure 2f). In the large majority of the cases, the reaction was focal. In 19 of the cases, the reaction was graded 
as $1+$ or $2+$, and in seven it was limited to scattered cells (trace). None of the mesotheliomas stained with this antibody.

\section{$B G-8$}

Out of the 45 serous carcinomas, $33(73 \%)$ reacted with the BG-8 antibody. In 14 of these cases, the staining was strong and diffuse $(3+$ or $4+)$. Only one mesothelioma was BG-8 positive. In this case, the staining was limited to a few tumor cells.

\section{CA19-9}

CA19-9 positivity was observed in 30 (67\%) of the 45 serous carcinomas. In the majority of these cases, the reaction was focal. None of the mesotheliomas expressed this marker.

\section{Leu-M1 (CD15)}

Out of the 45 serous carcinomas, 26 (58\%) reacted with the leu-M1 antibody. In the majority of the cases, the staining was focal and occurred along the cell membrane. None of the mesotheliomas stained with this antibody.

\section{Ultrastructural Findings}

The most common ultrastructural characteristics of the mesotheliomas were the presence of long, slender, often branching, undulating microvilli on the apical surface of the cuboidal cells lining the tubules or papillae (Figure 3a,b), dilated intercellular spaces (Figures 3a and 4), and intracellular lumens (Figures 5 and 6). On occasion, a profusion of microvilli was also seen on the basal surface of the cells (Figure 7a) or involving the entire cell membrane (Figure 7b). The cytoplasm usually exhibited large amounts of intermediate filaments often arranged in bundles (Figure 8). A variable amount of glycogen was also a common finding (Figure 6). A rare cell exhibiting a single cilium was identified in three of the cases, and, in one of these, the cilium was intracytoplasmic (Figure 9).

In the serous carcinomas, microvilli were present only on the luminal or papillary surfaces. They were usually straight, varied in length, and were fewer in number than in the mesotheliomas (Figures 10a and 11). The cell membranes were closely apposed and sometimes appeared to be interdigitating, especially in the low-grade tumors (Figure 12). Multiciliated cells were occasionally seen in some of the lowgrade serous tumors, and a large number of microvilli were distributed between the cilia on the surface of these cells (Figure 10a,b). A few or a single cilium were often found in the higher-grade serous carcinomas, but, in general, these structures tended to be less common in the less-differentiated tumors (Figure 13). Small bundles of intermediate filaments were only rarely identified in the cytoplasm of three cases.

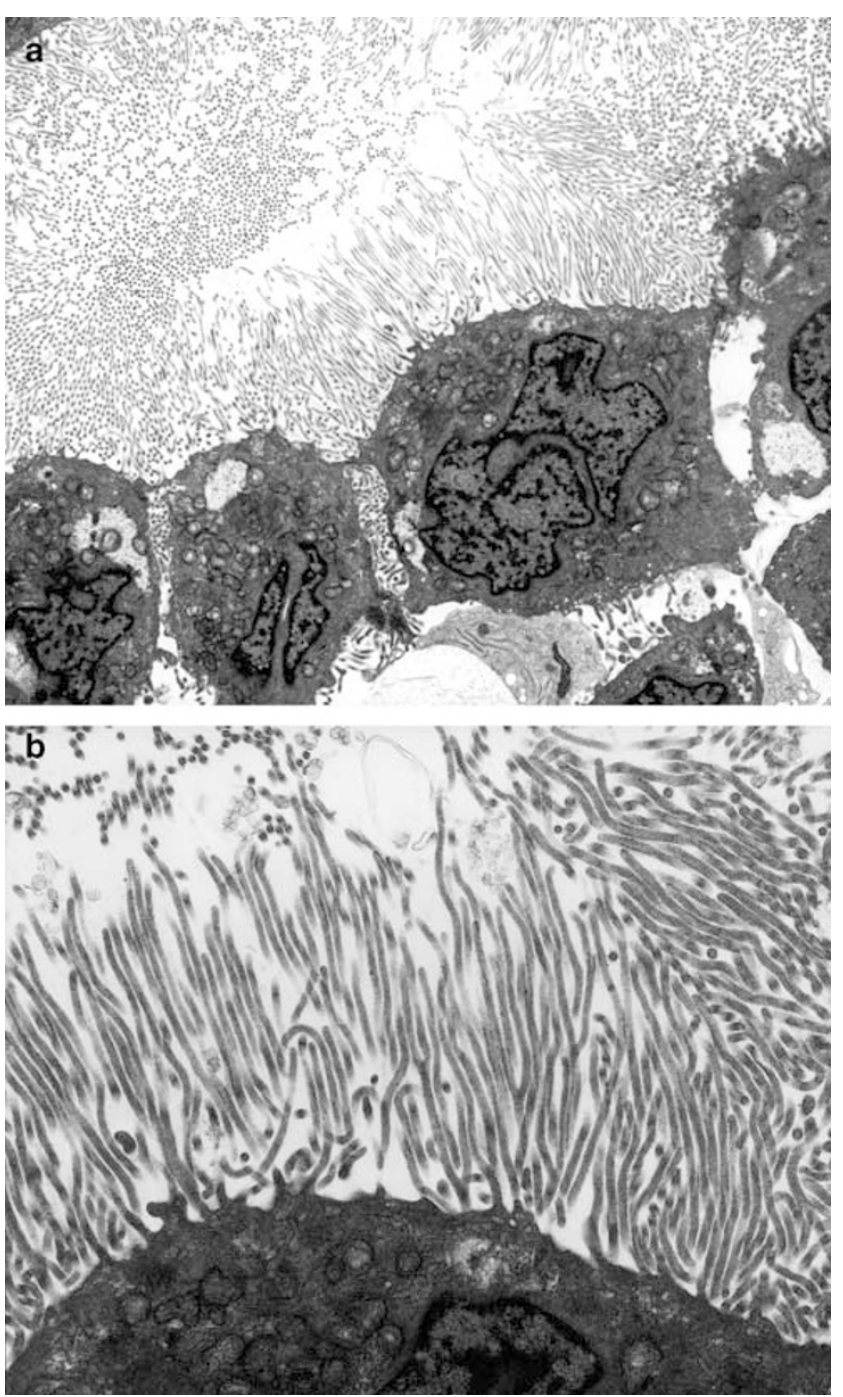

Figure 3 (a) A group of mesothelioma cells showing a profusion of microvilli on their apical surface. The intercellular spaces are dilated and the lateral cell membranes are also covered by microvilli. (b) Higher magnification electron micrograph of the same case as shown in (a), showing the typical wavy appearance of the microvilli. Branching of the microvilli is also apparent $(\mathbf{a}, \times 8000 ; \mathbf{b}, \times 20000)$.

\section{Discussion}

Mesotheliomas are one of the most intensively investigated tumors by immunohistochemical methods. New markers that may have a potential utility in this diagnosis are continually being recognized; however, the various reports that appear in the literature often contain conflicting results on the value of these markers. The primary focus of the large body of existing literature has been on the value of immunohistochemistry in establishing the differential diagnosis between pleural mesotheliomas and lung adenocarcinomas. Relatively little has been published on the value of this technique in distinguishing peritoneal mesotheliomas from ser- 


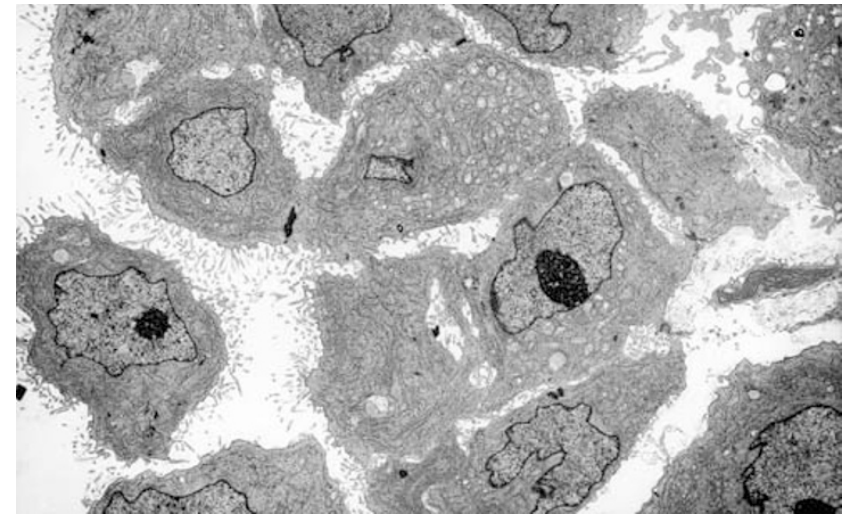

Figure 4 Although these mesothelioma cells do not display the same profusion of microvilli seen in the case in Figure 3a,b, the dilatation of the intercellular space together with the presence of microvilli along the lateral cell membrane support the diagnosis of mesothelioma over serous carcinoma. That the entire cell membrane seen in the lower left corner of the figure is covered by microvilli is also an indication that the tumor is a mesothelioma $(\times 3800)$.

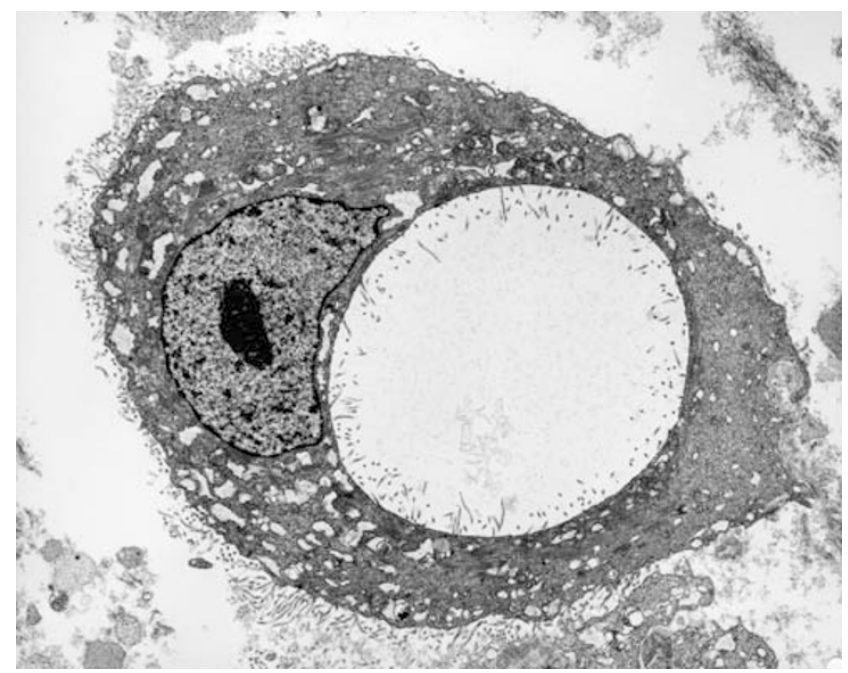

Figure 5 Mesothelioma cell with intracytoplasmic lumen. Microvilli can be seen along the cell membrane and the membrane limiting the lumen. Bundles of intermediate filaments are also apparent in the cytoplasm $(\times 4400)$.

ous papillary carcinomas of the ovary and peritoneum, even though, in my experience, this differential diagnosis can, in some instances, be even more challenging than that between pleural mesotheliomas and lung adenocarcinomas. Unfortunately, most of the markers that have proved to be very useful in the latter differential diagnosis do not have the same degree of sensitivity and/or specificity for distinguishing between peritoneal mesotheliomas and serous carcinomas of the ovary and peritoneum. For example, according to most investigators, CEA is not expressed in mesotheliomas, but it is present in over $75 \%$ of lung adenocarcinomas. ${ }^{9,26}$ As this marker has been reported in $0-45 \%$

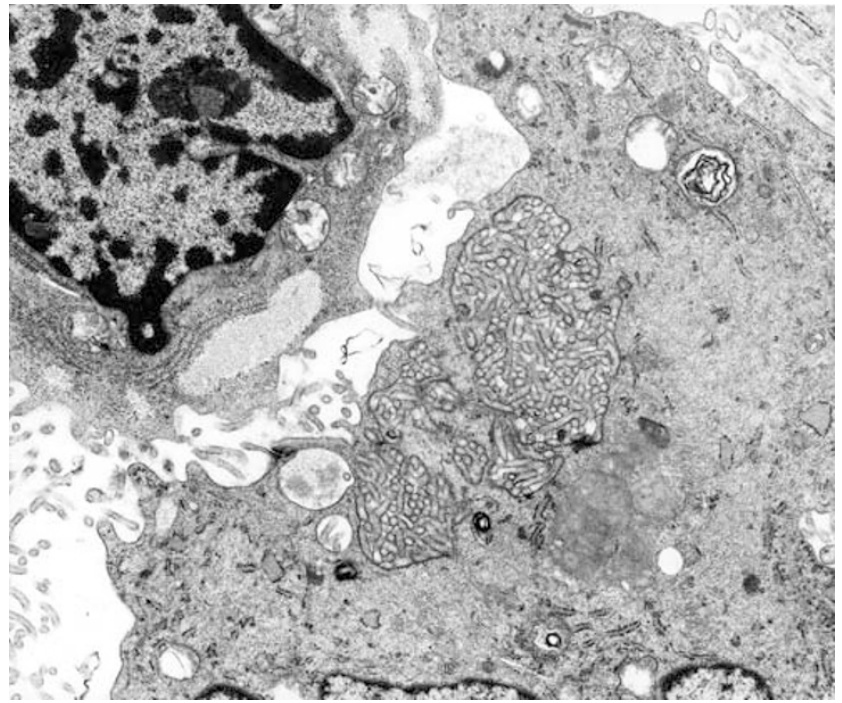

Figure 6 The mesothelioma cell on the right shows early development of what appears to be an intracytoplasmic lumen that is occupied by a profusion of microvilli, while the cell on the left shows small lakes of intracytoplasmic glycogen $(\times 15200)$.
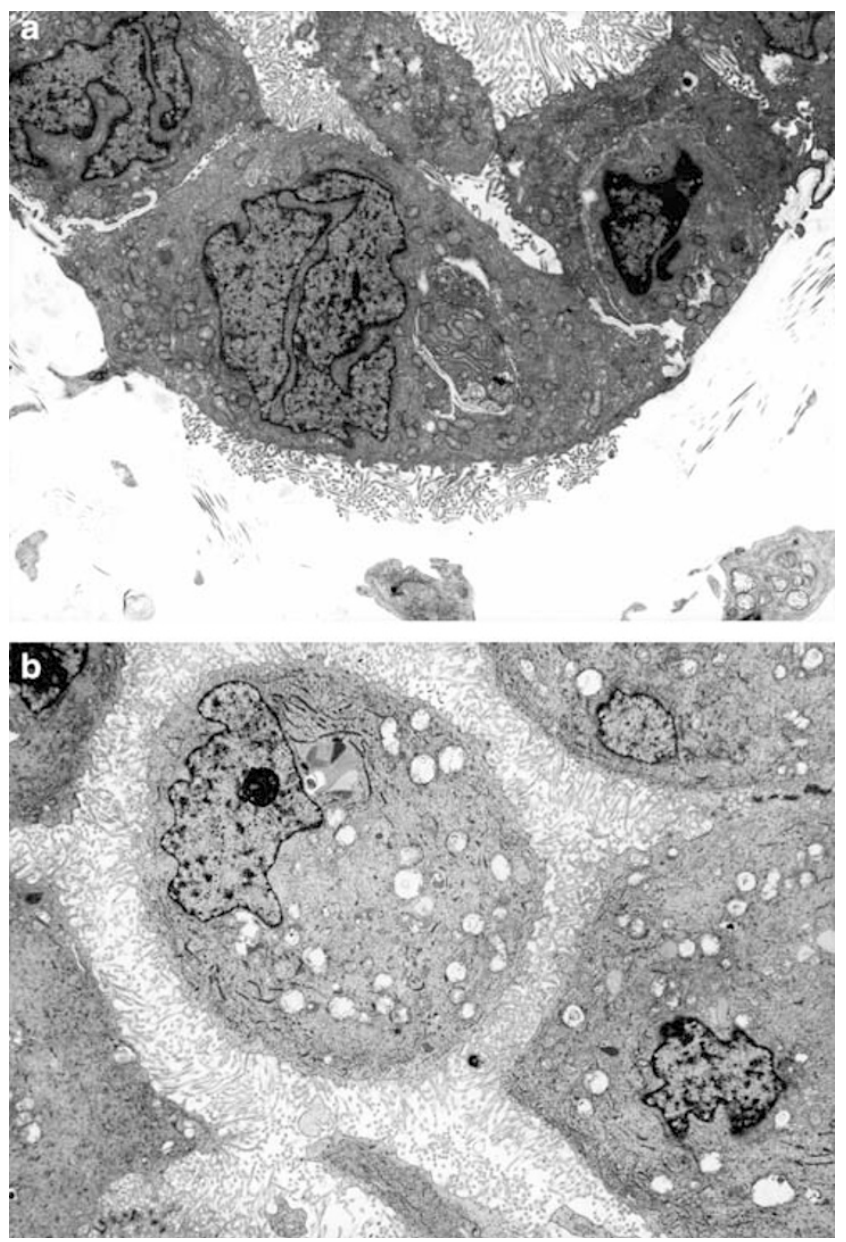

Figure 7 (a) The basal lamina, which is apparent on both the right and left sides of this figure, appears absent in the center, probably as a result of the proliferation of microvilli, which gives the impression of invading into the adjacent stroma $(\times 7600)$. (b) The entire cell membrane of the mesothelioma cell in the center of the figure is covered by microvilli $(\times 5300)$. 


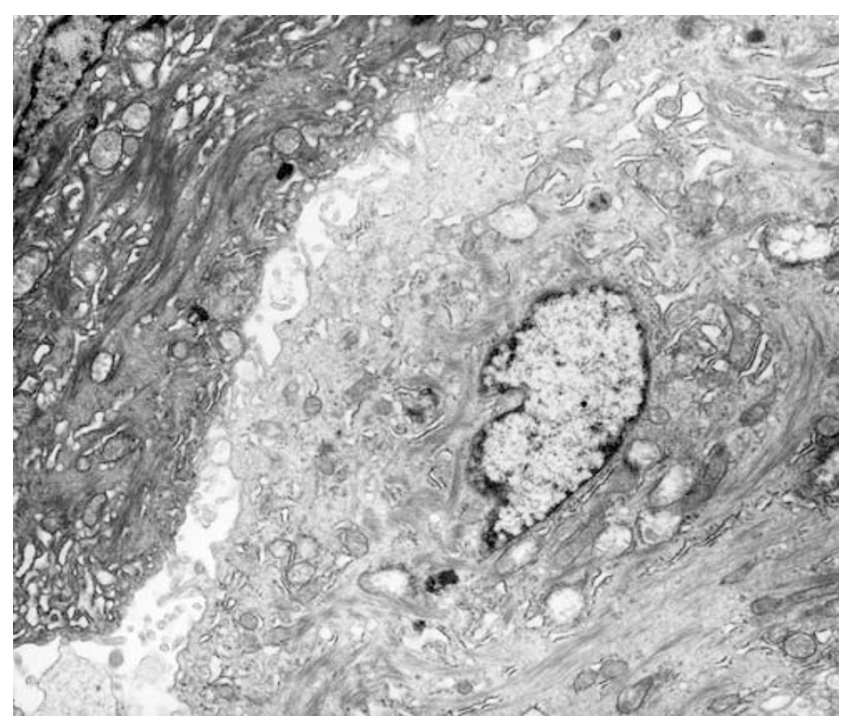

Figure 8 Mesothelioma cells showing numerous bundles of intermediate filaments $(\times 11700)$.

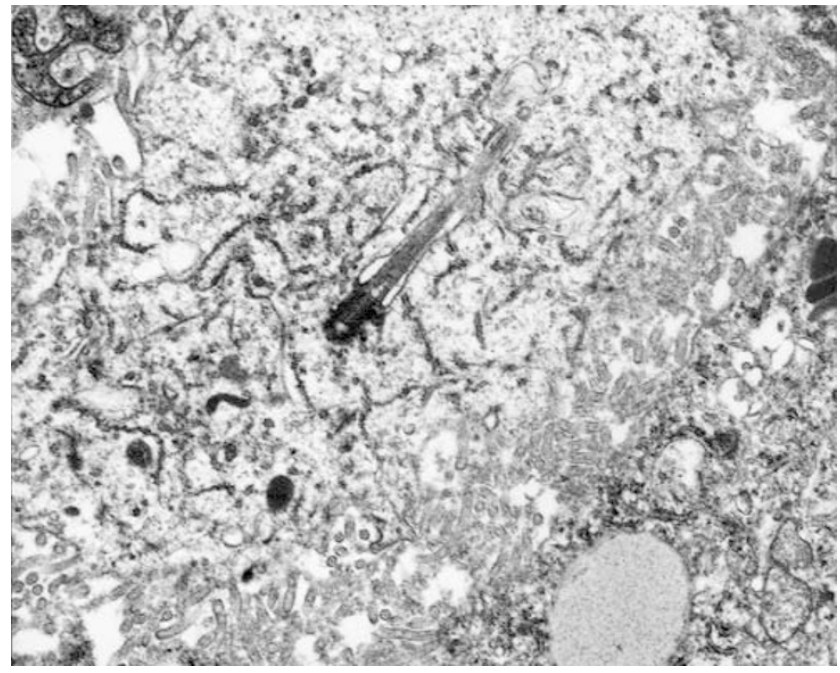

Figure 9 A mesothelioma cell showing an intracytoplasmic cilium $(\times 9000)$.

of serous carcinomas of the ovary and peritoneum,,$^{2,13,27,28}$ it has no practical utility in this differential diagnosis.

D2-40 is a mouse monoclonal antibody that reacts with a $40 \mathrm{kDa}$ O-linked sialoglycoprotein, better known as the oncofetal M2A antigen, in fetal germ cells and germ-cell tumors. ${ }^{29}$ It has been reported that, because the antigen recognized by this antibody is selectively expressed in lymphatic endothelium, it could be helpful for both the diagnosis of lymphatic-derived tumors and lymphatic invasion by tumors. ${ }^{16,17}$ In the present investigation, 37 (93\%) of the mesotheliomas showed D2-40 positivity, which was strong and diffuse in the large majority of the cases. This is comparable to the results
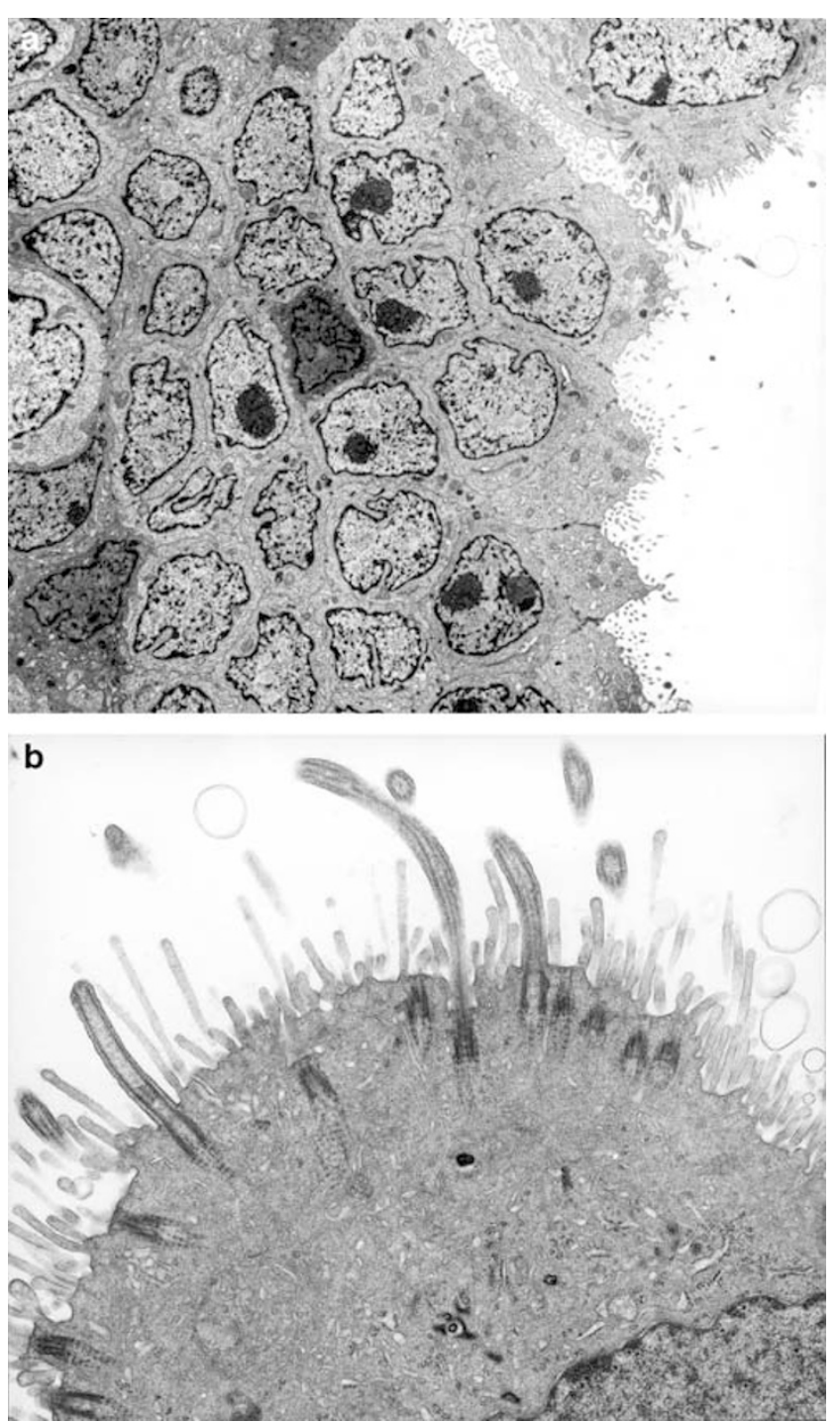

Figure 10 (a) Electron micrograph of a serous carcinoma. The cell membranes are closely apposed. The apical cell surface of some cells are covered by microvilli. A ciliated cell can be seen in the right upper corner of the figure. (b) Higher magnification of a ciliated cell of the same tumor as shown in (a). In addition to the cilia, the cell membrane appears to be covered by many microvilli, which exhibit a great variation in their lengths (a, $\times 5500 ; \mathbf{b}, \times 23000)$.

obtained by Chu et $a l,{ }^{20}$ who reported strong membranous reactivity in all $33(100 \%)$ epithelioid mesotheliomas and in the epithelioid component of $15(94 \%)$ of 16 biphasic mesotheliomas. The results reported by Sienko et $a{ }^{21}$ are somewhat different in that only $32(71 \%)$ of their 45 epithelioid mesotheliomas stained with the D2-40 antibody. The difference in the immunostaining results may be due, at least in part, to the utilization of a tissue microarray in the latter study. ${ }^{21}$ Six $(13 \%)$ of the 45 serous carcinomas in the present study showed focal membranous staining with the D2-40 antibody. These results are in contrast to those obtained by Chu et al, ${ }^{20}$ who reported focal D2-40 positivity in 


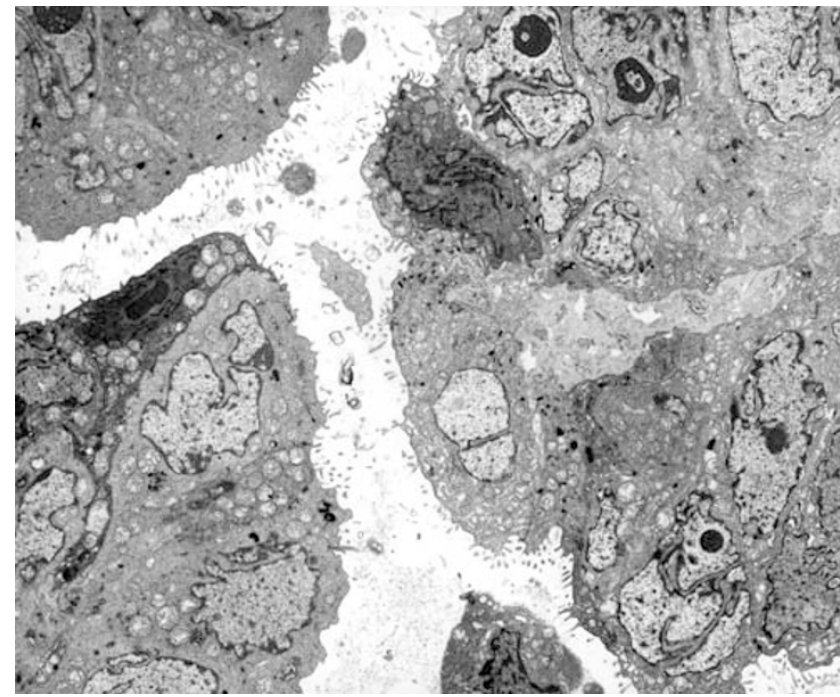

Figure 11 High-grade serous carcinoma. The nuclei are markedly irregular and often contain prominent nucleoli. The cell membranes are closely apposed and microvilli are restricted to the apical surface of the papillae $(\times 5000)$.

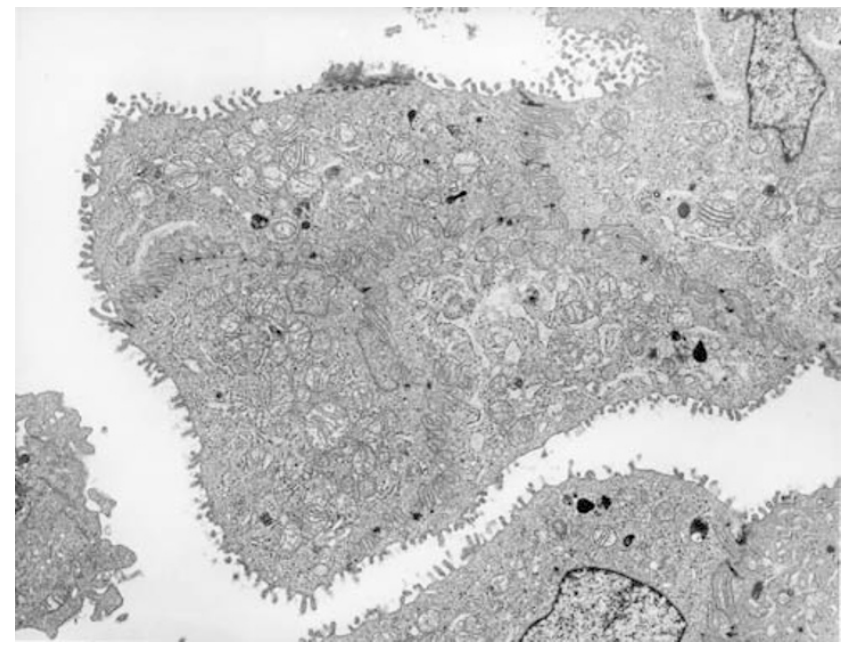

Figure 12 A group of serous carcinoma cells showing closely apposed interdigitating cell membranes $(\times 8000)$.

$17(65 \%)$ of 26 serous carcinomas. Given the fact that the same antibody dilution and a similar antigen retrieval procedure were used in both studies, the cause of the discrepancy between these results is unclear.

Originally detected on the surface of rat glomerular epithelial cells (podocytes), podoplanin is a $38 \mathrm{kDa}$ membrane mucoprotein that was found to be linked to the flattenting of foot processes in puromycin-induced nephrosis. ${ }^{30}$ Podoplanin displays the features of a type I membrane protein with several $O$-glycosylation sites. As similar proteins have been identified as counter-receptors for selectins which mediate inflammatory cell adhe-

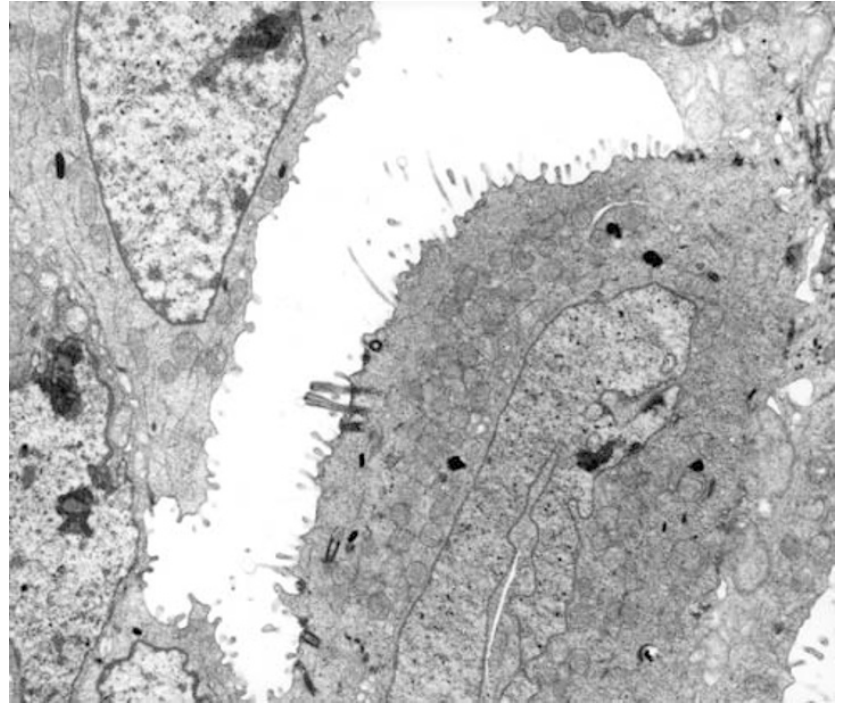

Figure 13 Same case as shown in Figure 12, showing several poorly developed cilia on the surface of one of the cells $(\times 10000)$.

sion, ${ }^{31}$ podoplanin may play a similar role in lymphatic endothelium. ${ }^{18}$ Recent investigations have shown that podoplanin can be used as a selective marker of lymphatic endothelium ${ }^{32,33}$ and that, like D2-40, it is expressed in lymphangiomas, Kaposi's sarcomas, and a subgroup of angiosarcomas, but not in endothelial cells of blood vessels. Kimura and Kimura ${ }^{22}$ recently reported podoplanin expression in five mesotheliomas, but in none of 93 adenocarcinomas of various origins, including six of the ovary. Based on these findings, they suggested that immunostaining for this marker could be useful in the diagnosis of mesothelioma. In the present investigation, $93 \%$ of the mesotheliomas and $13 \%$ of the serous carcinomas were podoplanin positive. This finding indicates that podoplanin has a similar specificity and sensitivity as D2-40 for discriminating between these malignancies.

Calretinin was first recognized as being a useful positive marker for the diagnosis of mesothelioma by Doglioni et al, ${ }^{34}$ who reported strong reactivity in all 36 epithelioid mesotheliomas, but only focal staining in $28(10 \%)$ of 294 adenocarcinomas of various origins. Although the utility of calretinin immunostaining in the diagnosis of mesothelioma was confirmed in subsequent studies, ${ }^{3,7,9,10,35,36}$ only a few investigations on the expression of this marker in serous carcinomas have been published ${ }^{1,2,20,34,37}$ (Table 3). In the present study, all of the mesotheliomas showed diffuse strong reactivity for calretinin, which confirms the findings of previous investigations, indicating that this marker is frequently expressed in these tumors. ${ }^{3,9,34,36}$ In all, 14 $(31 \%)$ of the 45 serous carcinomas also exhibited calretinin expression. In contrast to earlier investigations in which the staining for calretinin was reported as being either focal or negative,,$^{1,2,34}$ three 
Table 3 Calretinin reactivity reported in papillary serous carcinomas and peritoneal epithelioid mesothelioma

\begin{tabular}{|c|c|c|c|c|c|}
\hline & \multicolumn{2}{|c|}{ Papillary serous carcinomas } & \multicolumn{2}{|c|}{ Peritoneal epithelioid mesotheliomas } & \multirow[t]{2}{*}{ Antibody information } \\
\hline & $\mathrm{n}$ & + Cases (\%) & $\mathrm{n}$ & + Cases (\%) & \\
\hline Doglioni et al $(1996)^{34}$ & 16 & $1(6)$ & 3 & $3(100)$ & PAb, Swant \\
\hline Ordóñez $(1998)^{2}$ & 45 & $4(9)$ & 35 & $35(100)$ & PAb, Zymed \\
\hline Attanoos et al (2002) & 23 & $0(0)$ & 32 & $28(88)$ & PAb, Swant \\
\hline Cathro and Stoler (2005) ${ }^{37}$ & 13 & $5(38)$ & \multirow{2}{*}{\multicolumn{2}{|c|}{ Not studied }} & PAb, Swant \\
\hline Chu et al $(2005)^{20}$ & 26 & $8(31)$ & Not studied & & PAb, Zymed \\
\hline Present study & 45 & $14(31)$ & 40 & $40(100)$ & PAb, Zymed \\
\hline
\end{tabular}

$\mathrm{PAb}=$ polyclonal antibody

of the serous carcinomas in the present study exhibited strong reactivity $(3+)$, a finding which indicates that the specificity of this marker for discriminating between serous carcinomas and peritoneal epithelioid mesotheliomas is lower than previously thought. Two of these three cases were found to be strongly positive for Ber-EP4, but negative for keratin 5/6. Of these two cases, one was negative for MOC-31 and the other exhibited trace positivity. Owing to these results, electron microscopy studies were performed and only afterwards was it possible to establish the diagnosis of serous carcinoma.

Keratin 5/6 is another positive mesothelioma marker that, like calretinin, has also been proven to be helpful in the diagnosis of mesothelioma. ${ }^{9,35,38,39}$ Although the utility of this marker in discriminating between pleural mesotheliomas and lung adenocarcinomas has been well established, its value in differentiating between peritoneal mesotheliomas and serous carcinomas of the ovary and peritoneum is less clear (Table 4). In the present investigation, 37 (93\%) of the 40 mesotheliomas expressed keratin 5/6. The reaction was strong and diffuse in $22(59 \%)$ of these cases and focal in 15 $(41 \%)$. In all, $31 \%$ of the serous carcinomas also showed focal keratin 5/6 positivity. This finding indicates that keratin 5/6 immunostaining has only a limited value in discriminating between mesotheliomas and serous carcinomas of the ovary and peritoneum.

Thrombomodulin was the first of the positive mesothelioma markers that proved to be useful in the diagnosis of this tumor. Most studies have primarily focused on the utility of this marker in discriminating between mesotheliomas and lung adenocarcinomas, ${ }^{9,26,34,35,41-43}$ while only a few have investigated its value in differentiating peritoneal epithelioid mesotheliomas from serous carcinomas. ${ }^{1,2,44}$ The reported percentages of thrombomodulin expression in serous carcinomas have ranged from 2 to $35 \%$, and for peritoneal epithelioid mesotheliomas from 33 to $74 \%^{1,2,44}$ (Table 5). In the present investigation, $73 \%$ of the mesotheliomas and $4 \%$ of the serous carcinomas were thrombomodulin positive. Although the causes of the discre-
Table 4 Keratin 5/6 reactivity reported in papillary serous carcinomas and peritoneal epithelioid mesothelioma

\begin{tabular}{|c|c|c|c|c|}
\hline & \multicolumn{2}{|c|}{$\begin{array}{c}\text { Papillary serous } \\
\text { carcinomas }\end{array}$} & \multicolumn{2}{|c|}{$\begin{array}{c}\text { Peritoneal } \\
\text { epithelioid } \\
\text { mesotheliomas }\end{array}$} \\
\hline & $\mathrm{n}$ & $\begin{array}{c}+ \text { Cases } \\
(\%)\end{array}$ & $\mathrm{n}$ & $\begin{array}{c}+ \text { Cases } \\
(\%)\end{array}$ \\
\hline Ordóñez $(1998)^{2}$ & 45 & $11(24)$ & 35 & $35(100)$ \\
\hline Attanoos et al (2002) ${ }^{1}$ & 23 & $5(22)$ & 32 & $17(53)$ \\
\hline Reis-Filho et al $(2003)^{40}$ & 32 & $11(34)$ & \multirow{2}{*}{\multicolumn{2}{|c|}{$\begin{array}{l}\text { Not studied } \\
\text { Not studied }\end{array}$}} \\
\hline Chu et al $(2005)^{20}$ & 26 & $9(35)$ & & \\
\hline Present study & 45 & $14(31)$ & 40 & 37 (93) \\
\hline
\end{tabular}

Table 5 Thrombomodulin reactivity reported in papillary serous carcinomas and peritoneal epithelioid mesothelioma

\begin{tabular}{|c|c|c|c|c|}
\hline & \multicolumn{2}{|c|}{$\begin{array}{l}\text { Papillary serous } \\
\text { carcinomas }\end{array}$} & \multicolumn{2}{|c|}{$\begin{array}{c}\text { Peritoneal } \\
\text { epithelioid } \\
\text { mesotheliomas }\end{array}$} \\
\hline & $\mathrm{n}$ & $\begin{array}{c}+ \text { Cases } \\
(\%)\end{array}$ & $\mathrm{n}$ & $\begin{array}{c}+ \text { Cases } \\
(\%)\end{array}$ \\
\hline Attanoos et al (1995) & 20 & $7(35)$ & 18 & $6(33)$ \\
\hline Ordóñez $(1998)^{2}$ & 45 & $1(2)$ & 35 & $26(74)$ \\
\hline Attanoos et al $(2002)^{1}$ & 23 & $6(26)$ & 32 & $18(56)$ \\
\hline Present study & 45 & $2(4)$ & 40 & $29(73)$ \\
\hline
\end{tabular}

pancies between the results obtained in this investigation and those reported by others ${ }^{1,44}$ is unclear, it is possible that the selection of the cases, prolonged fixation, or the interpretation of the immunostaining results may have played a role.

MOC-31 is a monoclonal antibody that reacts with a $38 \mathrm{kDa}$ epithelial associated protein that is commonly expressed in carcinomas, but not in mesotheliomas. ${ }^{2,9,45,46}$ In the present investigation, 44 (98\%) of the 45 serous carcinomas and two $(5 \%)$ of the 40 mesotheliomas stained with this antibody. The reaction in the serous carcinomas was often strong and diffuse, while, in the mesotheliomas, it was 
limited to small focal areas or to a few scattered cells. These findings confirm previous investigations indicating that MOC-31 immunostaining could be very helpful in discriminating serous carcinomas from epithelioid mesotheliomas. ${ }^{2}$

Ber-EP4 is a monoclonal antibody that reacts with an epithelial antigen of unknown function that is commonly expressed in a wide variety of carcinomas, but rarely in mesotheliomas. ${ }^{47,48}$ Although many studies have been published on the value of this marker in distinguishing between pleural mesotheliomas and lung adenocarcinomas, ${ }^{26,34,35,49}$ only a few have been done on the differential diagnosis between serous carcinomas of the ovary and peritoneum, and peritoneal epithelioid mesotheliomas $^{1,2}$ (Table 6). In the present investigation, $100 \%$ of the serous carcinomas and $13 \%$ of the mesotheliomas reacted with the Ber-EP4 antibody. These figures are comparable to those previously reported. ${ }^{1,2}$ Since the reactivity in the serous carcinomas was often strong and diffuse, in contrast to that seen in the mesotheliomas which, when it occurred, was usually focal, Ber-EP4 immunostaining could be useful in assisting in distinguishing between these tumors.

In 1985, Lafebvre et $a l^{52}$ reported strong B72.3 reactivity in $17(85 \%)$ of 20 lung adenocarcinomas, whereas only two $(20 \%)$ of 10 epithelioid mesotheliomas exhibited weak positivity and, because of this, they suggested that immunostaining with this antibody could be useful in assisting in the differential diagnosis between these two malignancies. Although the value of B72.3 in the diagnosis of mesothelioma was confirmed in many subsequent investigations, ${ }^{9,26,41,53}$ some controversy still exits regarding the percentages of adenocarcinomas and mesotheliomas that are positive for this marker. The reported percentage of positivity for adenocarcinomas of the lung has ranged from 35 to $100 \%,{ }^{9,41,53}$ and for mesotheliomas in general from 0 to $48 \% .^{7,9,41}$ The immunostaining results obtained in serous carcinomas and peritoneal epithelioid mesotheliomas that have been reported by different groups of investigators ${ }^{2,27,28,50,54-56}$ are summarized in Table 7. In the present investigation, $73 \%$ of the serous carcinomas and none of the mesotheliomas reacted with the B72.3 antibody. Since the majority of the serous carcinomas exhibited focal positivity while only a minority reacted strongly and diffusely, the sensitivity of B72.3 for discriminating serous carcinomas from mesotheliomas is low, especially when compared with other negative markers such as Ber-EP4 or MOC-31. The results of this study also indicate that B72.3 positivity in mesotheliomas should be regarded as a rare phenomenon.

Leu-M1 (CD15) was one of the first immunohistochemical markers that proved to be useful in the diagnosis of mesotheliomas. ${ }^{56,57}$ CD15 expression has been demonstrated in $30-80 \%$ of serous carcinomas $^{1,2,27,28,50,55,56}$ (Table 8). Although some series
Table 6 Ber-EP4 reactivity reported in papillary serous carcinomas and peritoneal epithelioid mesothelioma

\begin{tabular}{|c|c|c|c|c|}
\hline & \multicolumn{2}{|c|}{$\begin{array}{l}\text { Papillary serous } \\
\text { carcinomas }\end{array}$} & \multicolumn{2}{|c|}{$\begin{array}{c}\text { Peritoneal } \\
\text { epithelioid } \\
\text { mesotheliomas }\end{array}$} \\
\hline & $\mathrm{n}$ & $\begin{array}{c}+ \text { Cases } \\
(\%)\end{array}$ & $\mathrm{n}$ & $\begin{array}{c}+ \text { Cases } \\
(\%)\end{array}$ \\
\hline $\begin{array}{l}\text { Rothacker and } \\
\text { Möbius (1995) }\end{array}$ & 30 & $25(83)$ & \multicolumn{2}{|c|}{ Not studied } \\
\hline Ordóñez $(1998)^{2}$ & 45 & 45 (100) & 35 & $4(11)$ \\
\hline Cherchi et al (2001) ${ }^{51}$ & 6 & $3(50)$ & \multicolumn{2}{|c|}{ Not studied } \\
\hline Attanoos et al $(2002)^{1}$ & 23 & $20(87)$ & 32 & $3(9)$ \\
\hline Present study & 45 & $45(100)$ & 40 & $5(13)$ \\
\hline
\end{tabular}

Table 7 B72.3 reactivity reported in papillary serous carcinomas and peritoneal epithelioid mesothelioma

\begin{tabular}{|c|c|c|c|c|}
\hline & \multicolumn{2}{|c|}{$\begin{array}{l}\text { Papillary } \\
\text { serous } \\
\text { carcinomas }\end{array}$} & \multicolumn{2}{|c|}{$\begin{array}{c}\text { Peritoneal } \\
\text { epithelioid } \\
\text { mesotheliomas }\end{array}$} \\
\hline & $\mathrm{n}$ & $\begin{array}{c}+ \text { Cases } \\
(\%)\end{array}$ & $\mathrm{n}$ & $\begin{array}{c}+ \text { Cases } \\
(\%)\end{array}$ \\
\hline Thor et al (1986) ${ }^{54}$ & 47 & $46(98)$ & \multicolumn{2}{|c|}{ Not studied } \\
\hline Bollinger et al (1989) ${ }^{27}$ & 46 & $33(72)$ & 28 & $0(0)$ \\
\hline Wick et al (1989) ${ }^{55}$ & 44 & $37(84)$ & \multicolumn{2}{|c|}{ Not studied } \\
\hline Khoury et al $(1990)^{28}$ & 20 & $13(65)$ & 10 & $3^{\mathrm{a}}(30)$ \\
\hline Wick et al $(1990)^{56}$ & 10 & $10(100)$ & 20 & $0(0)$ \\
\hline Rothacker and Möbius (1995) & 30 & $27(90)$ & \multicolumn{2}{|c|}{ Not studied } \\
\hline Ordóñez (1998)² & 45 & $39(87)$ & 35 & $0(0)$ \\
\hline Present study & 45 & $33(73)$ & 40 & $0(0)$ \\
\hline
\end{tabular}

${ }^{\mathrm{a}}<1 \%$ of the cells were positive.

Table 8 CD15 reactivity reported in papillary serous carcinomas and peritoneal epithelioid mesothelioma

\begin{tabular}{|c|c|c|c|c|}
\hline & \multicolumn{2}{|c|}{$\begin{array}{l}\text { Papillary } \\
\text { serous } \\
\text { carcinomas }\end{array}$} & \multicolumn{2}{|c|}{$\begin{array}{l}\text { Peritoneal } \\
\text { epithelioid } \\
\text { mesotheliomas }\end{array}$} \\
\hline & $\mathrm{n}$ & $\begin{array}{c}+ \text { Cases } \\
(\%)\end{array}$ & $\mathrm{n}$ & $\begin{array}{c}+ \text { Cases } \\
(\%)\end{array}$ \\
\hline Bollinger et al (1989) ${ }^{27}$ & 46 & $34(74)$ & 28 & $3(11)$ \\
\hline Wick et al (1989) ${ }^{55}$ & 44 & $32(73)$ & \multicolumn{2}{|c|}{ Not studied } \\
\hline Khoury et al (1990) ${ }^{28}$ & 20 & $6(30)$ & 4 & $0(0)$ \\
\hline Wick et al $(1990)^{56}$ & 10 & $8(80)$ & 20 & $3(15)$ \\
\hline Rothacker and Möbius (1995) ${ }^{50}$ & 30 & $17(57)$ & \multicolumn{2}{|c|}{ Not studied } \\
\hline Ordóñez $(1998)^{2}$ & 45 & $28(62)$ & 35 & $0(0)$ \\
\hline Attanoos et al $(2002)^{1}$ & 23 & $7(30)$ & 32 & $2(6)$ \\
\hline Present study & 45 & $26(58)$ & 40 & $0(0)$ \\
\hline
\end{tabular}

have also reported positivity in a minority of mesotheliomas, ${ }^{3,13,41,58}$ in the present investigation, as well as in previous studies by this author ${ }^{2,9,26}$ and others, ${ }^{56,57,59}$ none of the mesotheliomas exhibited 
CD15 expression. In the current investigation, only $56 \%$ of the serous carcinomas expressed CD15. These results indicate that this marker has a low sensitivity for distinguishing between serous carcinomas and epithelioid mesotheliomas.

CA19-9 is a sialynated lacto- $N$-fucopentaose II related to the Lewis ${ }^{\mathrm{a}}$ blood group ${ }^{60}$ that is commonly expressed in adenocarcinomas of the ovary, ${ }^{61,62}$ pancreas, ${ }^{60}$ gastrointestinal tract, ${ }^{60,61}$ and lung, ${ }^{63}$ but not in mesotheliomas. ${ }^{2,64}$ In the present investigation, CA19-9 expression was demonstrated in $67 \%$ of the serous carcinomas, but in none of the mesotheliomas. This finding indicates that, even though CA19-9 is $100 \%$ specific for discriminating between serous carcinomas and peritoneal mesotheliomas, its sensitivity is rather low, thus limiting its practical utility.

BG-8 is a monoclonal antibody that recognizes the blood group antigen Lewis ${ }^{\mathrm{Y}}{ }^{12}$ In 1997 , Riera et al, ${ }^{13}$ using this antibody, demonstrated Lewis ${ }^{\mathrm{Y}}$ expression in 187 (89\%) of 211 adenocarcinomas of various origins, but in only five $(9 \%)$ of 57 epithelioid mesotheliomas. As the majority of the adenocarcinomas exhibited a diffuse strong positivity, while the staining in the mesotheliomas was focal and weak, these investigators concluded that BG-8 immunostaining could assist in distinguishing epithelioid mesotheliomas from adenocarcinomas. In the present study, $73 \%$ of the serous carcinomas reacted with the BG-8 antibody and, in the majority of cases, the staining was strong and diffuse. In contrast, only one $(3 \%)$ of the mesotheliomas stained with this antibody and the reaction occurred in a limited number of cells.

In all of the cases in which electron microscopy studies were performed, this technique allowed the differential diagnosis to be clearly established between epithelioid mesothelioma and serous carcinoma. The mesotheliomas were characterized by a profusion of long, slender, wavy microvilli occurring along any of the surfaces of the cells. This is in contrast to the serous carcinomas in which the microvilli were less numerous, and straight, and, although they were of varying lengths, they were in general shorter and confined to the luminal and papillary surfaces. Additionally, the cell membranes in the serous carcinomas were intimately apposed, while, in the mesotheliomas, intercellular gaps that often exhibited microvilli were a common finding. Similar to previous ultrastructural studies, large collections of intermediate filaments arranged in tonofibrillar bundles and intracytoplasmic lumens covered by microvilli were common findings in mesotheliomas, ${ }^{65-67}$ but not in serous carcinomas. ${ }^{68-70}$ No intracytoplasmic lumens were identified in any of the serous carcinomas investigated, and only rare small bundles of intermediate filaments were found in a few cases. Another finding that was helpful in distinguishing serous carcinomas from mesotheliomas was the presence of multiciliated cells in serous carcinomas, but not in mesotheliomas. Multiciliated cells, such as those shown in Figure 10a and b, have previously been reported in serous carcinomas and are more often found in low-grade serous carcinomas and serous tumors of borderline malignancy originating in the ovary and peritoneum. ${ }^{23,24,69-72}$ Neither in the present study nor in previous investigations have these cells been found in mesotheliomas. Cells presenting a solitary cilium or a few cilia have frequently been found in serous carcinomas, including those of high-grade malignancy; however, their occurrence in mesotheliomas is exceedingly rare. ${ }^{73,74}$

The results of this investigation indicate that, because of their sensitivity and specificity, Ber-EP4 and MOC-31 are the best of the negative mesothelioma markers. Ber-EP4 positivity was observed in $100 \%$ of the serous carcinomas, and in nearly all of the cases the staining was strong and diffuse, in contrast to the mesotheliomas in which $13 \%$ reacted for this marker in sparse cells or small areas of the tumor. The sensitivity of MOC-31 is comparable to that of Ber-EP4 in that the large majority of serous carcinomas are strongly positive for this marker, but its specificity appears to be higher since only $5 \%$ of the mesotheliomas exhibited positivity for this marker in a few cells. All of the other negative markers investigated may also be useful, but they are less sensitive than either Ber-EP4 or MOC-31. Like the other positive mesothelioma markers, neither D2-40 nor podoplanin are absolutely specific for epithelioid mesotheliomas. Their specificity is higher than that of calretinin, but their sensitivity is somewhat lower. Thrombomodulin appears to be highly specific for mesotheliomas, but its sensitivity is lower than the previously mentioned markers. Keratin 5/6 has no practical utility in discriminating between epithelioid mesotheliomas and serous carcinomas. From a practical point of view, using Ber-EP4 and MOC-31 in combination with calretinin and/or D2-40 or podoplanin will usually make it possible to distinguish between serous carcinomas and mesotheliomas. Since it was possible to make a clear distinction between the mesotheliomas and serous carcinomas in all of the cases in which electron microscopy studies were performed, this technique can be extremely useful in establishing the correct diagnosis in those cases in which the immunohistochemical results are equivocal or a further substantiation of a diagnosis of mesothelioma is needed for medical or legal purposes.

\section{Acknowledgements}

I thank Ms Janet Quinones, Ms Raju Nandagiri, Ms Maria Grimberg and Mr Mannie Steglich for technical assistance and Ms Asuncion Moroi for secretarial assistance. 


\section{References}

1 Attanoos RL, Webb R, Dojcinov SD, et al. Value of mesothelial and epithelial antibodies in distinguishing diffuse peritoneal mesothelioma in females from serous papillary carcinoma of the ovary and peritoneum. Histopathology 2002;40:237-244.

2 Ordóñez NG. Role of immunohistochemistry in distinguishing epithelial peritoneal mesotheliomas from peritoneal and ovarian serous carcinomas. Am J Surg Pathol 1998;22:1203-1214.

3 Leers MPG, Aarts MMJ, Theunissen PHMH. E-cadherin and calretinin: a useful combination of immunochemical markers for differentiation between mesothelioma and metastatic adenocarcinoma. Histopathology 1998;32:209-216.

4 Ordóñez NG. Value of E-cadherin and N-cadherin immunostaining in the diagnosis of mesothelioma. Hum Pathol 2003;34:749-755.

5 Ordóñez NG. Value of thyroid transcription factor-1, Ecadherin, BG8, WT1, and CD44S immunostaining in distinguishing epithelial pleural mesothelioma from pulmonary and nonpulmonary adenocarcinoma. Am J Surg Pathol 2000;24:598-606.

6 Peralta-Soler A, Knudsen KA, Jaurand MC, et al. The differential expression of $\mathrm{N}$-cadherin and E-cadherin distinguishes pleural mesotheliomas from lung adenocarcinomas. Hum Pathol 1995;26:1363-1369.

7 Ordóñez NG. The diagnostic utility of immunohistochemistry in distinguishing between mesothelioma and renal cell carcinoma: a comparative study. Hum Pathol 2004;35:697-710.

8 Oates J, Edwards C. HBME-1, MOC-31, WT1 and calretinin: as assessment of recently described markers for mesothelioma and adenocarcinoma. Histopathology 2000;36:341-347.

9 Ordóñez NG. The immunohistochemical diagnosis of mesothelioma: a comparative study of epithelioid mesothelioma and lung adenocarcinoma. Am J Surg Pathol 2003;27:1031-1051.

10 Cury PM, Butcher DN, Fisher C, et al. Value of the mesothelium-associated antibodies thrombomodulin, cytokeratin 5/6, calretinin, and $\mathrm{CD} 44 \mathrm{H}$ in distinguishing epithelioid pleural mesothelioma from adenocarcinoma metastatic to the pleura. Mod Pathol 2000; 13:107-112.

11 Ordóñez NG. Value of mesothelin immunostaining in the diagnosis of mesothelioma. Mod Pathol 2003;16: 192-197.

12 Jordon D, Jagirdar J, Kaneko M. Blood group antigens, Lewis $^{\mathrm{x}}$ and Lewis ${ }^{\mathrm{y}}$, in the diagnostic discrimination of malignant mesothelioma versus adenocarcinoma. Am J Pathol 1989;135:931-937.

13 Riera JR, Astengo-Osuna C, Longmate JA, et al. The immunohistochemical diagnostic panel for epithelial mesothelioma. A reevaluation after heat-induced epitope retrieval. Am J Surg Pathol 1997;21: 1409-1419.

14 Ordóñez NG. Application of mesothelin immunostaining in tumor diagnosis. Am J Surg Pathol 2003;27: 1418-1428.

15 Chang K, Pai LH, Pass H, et al. Monoclonal antibody K1 reacts with epithelial mesothelioma but not with lung adenocarcinoma. Am J Surg Pathol 1992;16: 259-268.

16 Kahn HJ, Bailey D, Marks A. Monoclonal antibody D2-40, a new marker of lymphatic endothelium, reacts with Kaposi's sarcoma and a subset of angiosarcomas. Mod Pathol 2002;15:434-440.

17 Kahn HJ, Marks A. A new monoclonal antibody, D2-40, for detection of lymphatic invasion in primary tumors. Lab Invest 2002;82:1255-1257.

18 Breiteneder-Geleff S, Soleiman A, Horvat R, et al. Podoplanin-a specific marker for lymphatic endothelium expressed in angiosarcoma. Verh Deut Gesell Pathol 1999;83:270-275.

19 Breiteneder-Geleff S, Soleiman A, Kowalski H, et al. Angiosarcomas express mixed endothelial phenotypes of blood and lymphatic capillaries: podoplanin as a specific marker for lymphatic endothelium. Am J Pathol 1999;154:385-394.

20 Chu AY, Litzky LA, Pasha TL, et al. Utility of D2-40, a novel mesothelial marker, in the diagnosis of malignant mesothelioma. Mod Pathol 2005;18:105-110.

21 Sienko A, Zander DS, Killen D, et al. D2-40 is a novel new marker of malignant mesothelioma (MM): tissue microarray study of $45 \mathrm{MM}$ versus 409 lung carcinomas and primary non-mesothelial neoplasms of the pleura and chest wall. Mod Pathol 2005; 18(Suppl 1):318A.

22 Kimura N, Kimura I. Podoplanin as a marker for mesothelioma. Pathol Int 2005;55:83-86.

23 Raju U, Fine G, Greenawald KA, et al. Primary papillary serous neoplasia of the peritoneum: a clinicopathologic and ultrastructural study of eight cases. Hum Pathol 1989;20:426-436.

24 Warhol MJ, Hunter NJ, Corson JM. An ultrastructural comparison of mesotheliomas and adenocarcinomas of the ovary and endometrium. Int J Gynecol Pathol 1982; $1: 125-134$

25 Churg A, Roggli V, Galateau-Salle F, et al. Mesothelioma. In: Travis WD, Brambilla E, Müller-Hermelink HK, Harris CC (eds). World Health Organization Classification of Tumours Pathology and Genetics: Tumours of the Lung, Pleura, Thymus and Heart. IARC Press: Lyon, France, 2004;128-136.

26 Ordóñez NG. Value of antibodies 44-3A6, SM3, HBME1 and thrombomodulin in differentiating epithelial pleural mesothelioma from lung adenocarcinoma: a comparative study with other commonly used antibodies. Am J Surg Pathol 1997;21:1399-1408.

27 Bollinger DJ, Wick MR, Dehner LP, et al. Peritoneal malignant mesothelioma versus serous papillary adenocarcinoma: a histochemical and immunohistochemical comparison. Am J Surg Pathol 1989;13: 659-670.

28 Khoury N, Raju U, Crissman JD, et al. A comparative immunohistochemical study of peritoneal and ovarian serous tumors, and mesotheliomas. Hum Pathol 1990; 21:811-819.

29 Marks A, Sutherland DR, Bailey D, et al. Characterization and distribution of an oncofetal antigen (M2A antigen) expressed on testicular germ cell tumours. Br J Cancer 1999;80:569-578.

30 Breiteneder-Geleff S, Matsui K, Soleiman A, et al. Podoplanin, novel 43-kd membrane protein of glomerular epithelial cells, is down-regulated in puromycin nephrosis. Am J Pathol 1997;151:1141-1152.

31 Sassetti C, Tangemann K, Singer MS, et al. Identification of podocalyxin-like protein as a high endothelial venule ligand for L-selectin: parallels to CD34. J Exp Med 1998;187:1965-1975.

32 Birner P, Schindl M, Obermair A, et al. Lymphatic microvessel density as a novel prognostic factor in 
early-stage invasive cervical cancer. Int J Cancer (Pred Oncol) 2001;95:29-33.

33 Sinzelle E, Duong Van Huyen JP, Breiteneder-Geleff S, et al. Intrapericardial lymphangioma with podoplanin immunohistochemical characterization of lymphatic endothelial cells. Histopathology 2000;37:93-94.

34 Doglioni C, Dei Tos AP, Laurino L, et al. Calretinin: a novel immunocytochemical marker for mesothelioma. Am J Surg Pathol 1996;20:1037-1046.

35 Carella R, Deleonardi G, D’Errico A, et al. Immunohistochemical panels for differentiating epithelial malignant mesothelioma from lung adenocarcinoma: a study with logistic regression analysis. Am J Surg Pathol 2001;25:43-50.

36 Ordóñez NG. Value of calretinin immunostaining in differentiating epithelial mesothelioma from lung adenocarcinoma. Mod Pathol 1998;11:929-933.

37 Cathro HP, Stoler MH. The utility of calretinin, inhibin, and WT1 immunohistochemical staining in the differential diagnosis of ovarian tumors. Hum Pathol 2005;36:195-201.

38 Clover J, Oates J, Edwards C. Anti-cytokeratin 5/6: a positive marker for epithelioid mesothelioma. Histopathology 1997;31:140-143.

39 Ordóñez NG. Value of cytokeratin 5/6 immunostaining in distinguishing epithelial mesothelioma of the pleura from lung adenocarcinoma. Am J Surg Pathol 1998;22:1215-1221.

40 Reis-Filho JS, Simpson PT, Martins A, et al. Distribution of p63, cytokeratins 5/6 and cytokeratin 14 in 51 normal and 400 neoplastic human tissue samples using TARP-4 multi-tumor tissue microarray. Virchows Arch 2003;443:122-132.

41 Brown RW, Clark GM, Tandon AK, et al. Multiplemarker immunohistochemical phenotypes distinguishing malignant pleural mesothelioma from pulmonary adenocarcinoma. Hum Pathol 1993;24:347-354.

42 Collins CL, Ordóñez NG, Schaefer R, et al. Thrombomodulin expression in malignant pleural mesothelioma and pulmonary adenocarcinoma. Am J Pathol 1992;141:827-833.

43 Ordóñez NG. Value of thrombomodulin immunostaining in the diagnosis of mesothelioma. Histopathology 1997;31:25-30.

44 Attanoos RL, Appleton MAC, Goddard H, et al. Thrombomodulin expression in malignant peritoneal mesothelioma and serous papillary adenocarcinoma of the ovary. J Pathol 1995;176:S49A.

45 Edwards C, Oates J. OV632 and MOC-31 in the diagnosis of mesothelioma and adenocarcinoma: an assessment of their use in formalin-fixed paraffin wax embedded material. J Clin Pathol 1995;48:626-630.

46 Ordóñez NG. Value of the MOC-31 monoclonal antibody in differentiating epithelial pleural mesothelioma from lung adenocarcinoma. Hum Pathol 1998;29: 166-169.

47 Latza U, Niedobitek G, Schwarting R, et al. Ber-EP4: new monoclonal antibody which distinguishes epithelia from mesothelia. J Clin Pathol 1990;43:213-219.

48 Ordóñez NG. Value of the Ber-EP4 antibody in differentiating epithelial pleural mesothelioma from adenocarcinoma: the MD Anderson experience and a critical review of the literature. Am J Clin Pathol 1998;109:85-89.

49 Maguire B, Whitaker D, Carrello S, et al. Monoclonal antibody Ber-EP4: its use in the differential diagnosis of malignant mesothelioma and carcinoma in cell blocks of malignant effusions and FNA specimens. Diagn Cytopathol 1994;10:130-134.

50 Rothacker D, Möbius G. Varieties of serous surface papillary carcinoma of the peritoneum in northern Germany: a thirty-year autopsy study. Int J Gynecol Pathol 1995;14:310-318.

51 Cherchi PL, Marras V, Capobianco G, et al. Immunohistochemical evaluation of a new epithelial antigen, Ber-EP4, in ovarian cancer: preliminary results. Eur J Gynaec Oncol 2001;22:433-435.

52 Lafebvre MP, Rodriguez F, Schlom J, et al. The application of a monoclonal antibody to the differentiation of benign and malignant mesothelial proliferations from adenocarcinomas (abstract). Lab Invest 1985;52:38A.

53 Warnock ML, Stoloff A, Thor A. Differentiation of adenocarcinoma of the lung from mesothelioma. Periodic acid-Schiff, monoclonal antibodies B72.3, and Leu M1. Am J Pathol 1988;133:30-38.

54 Thor A, Gorstein F, Ohuchi N, et al. Tumor-associated glycoprotein (TAG-72) in ovarian carcinomas defined by monoclonal antibody B72.3. JNCI 1986;76: 995-1006.

55 Wick MR, Mills SE, Dehner LP, et al. Serous papillary carcinomas arising from the peritoneum and ovaries: a clinicopathologic and immunohistochemical comparison. Int J Gynecol Pathol 1989;8:179-188.

56 Wick MR, Mills SE, Swanson PE. Expression of 'myelomonocytic' antigens in mesotheliomas and adenocarcinomas involving the serosal surfaces. Am J Clin Pathol 1990;94:18-26.

57 Sheibani K, Battifora H, Burke JS, et al. Leu-M1 antigen in human neoplasms: an immunohistologic study of 400 cases. Am J Surg Pathol 1986;10:227-236.

58 González-Lois C, Ballentín C, Sotelo MT, et al. Combined use of novel epithelial (MOC-31) and mesothelial (HBME-1) immunohistochemical markers for optimal first line diagnostic distinction between mesothelioma and metastatic carcinoma in pleura. Histopathology 2001;38:528-534.

59 Gaffey MJ, Mills SE, Swanson PE, et al. Immunoreactivity for BER-EP4 in adenocarcinomas, adenomatoid tumors, and malignant mesotheliomas. Am J Surg Pathol 1992;16:593-599.

60 Magnani JL, Steplewski Z, Koprowski H, et al. Identification of the gastrointestinal and pancreatic cancer-associated antigen detected by monoclonal antibody 19-9 in the sera of patients as a mucin. Cancer Res 1983;43:5489-5492.

61 Lagendijk JH, Mullink H, Van Diest PJ, et al. Tracing the origin of adenocarcinomas with unknown primary using immunohistochemistry: differential diagnosis between colonic and ovarian carcinomas as primary sites. Hum Pathol 1998;29:491-497.

62 Ordóñez NG, Freedman RS, Herlyn M. Lewis and related tumor-associated determinants on ovarian carcinoma. Gynecol Oncol 1987;26:1-10.

63 Oshio G, Yamaki K, Imamura T, et al. Distribution of the carbohydrate antigens, DU-PAN-2 and CA19-9, in tumors of the lung. Tumori 1995;81:67-73.

64 Chenard-Neu MP, Bellocq JP, Maier A, et al. Mésothéliomes malins de la plévre. Analyse de leurs aspects immunohistochemiques. Ann Pathol 1990;10: 20-27.

65 Coleman M, Henderson DW, Mukherjee TM. The ultrastructural pathology of malignant pleural mesothelioma. Part I. Pathol Ann 1989;24:303-353. 
66 Dardick I, Jabi M, McCaughey WTE, et al. Diffuse epithelial mesothelioma: a review of the ultrastructural spectrum. Ultrastruct Pathol 1987;11:503-533.

67 Oury TD, Hammar SP, Roggli VL. Ultrastructural features of diffuse malignant mesotheliomas. Hum Pathol 1998;29:1382-1392.

68 Blaustein A. Papillary serous tumors of the ovary: an electron microscopic study. Gynecol Oncol 1976;4: 314-323.

69 Gondos B. Electron microscopic study of papillary serous tumors of the ovary. Cancer 1971;27: 1455-1464.

70 Roberts DK, Marshall RB, Wharton JT. Ultrastructure of ovarian tumors. I. Papillary serous cystadenocarcinoma. Cancer 1970;25:947-958.
71 Ferenczy A. Electron microscopy of histologically difficult to diagnose gynecologic neoplasms. Ultrastruct Pathol 1987;11:335-360.

72 Gooneratne S, Sassone M, Blaustein A, et al. Serous surface papillary carcinoma of the ovary: a clinicopathologic study of 16 cases. Int J Gynecol Pathol 1982;1:258-269.

73 Dumke K, Schnoy N, Specht G, et al. Comparative light and electron microscopic studies of cystic and papillary tumors of the peritoneum. Virchows Arch (Pathol Anat) 1983;399:25-39.

74 Torikata C, Kawai T, Nakayama M. Confronting cisternae and ciliated cells in malignant pleural mesothelioma: an ultrastructural study. Ultrastruct Pathol 1991;15:249-256. 